\title{
MANUFACTURE OF ACTIVATED CARBON FROM RUBBER WOOD FOR TAILOR-MADE APPLICATIONS
}

\author{
Lima Rose Miranda' and Annam Renita A. ${ }^{2}$ \\ ${ }^{1}$ Department of Chemical Engineering, Anna University, Chennai, India \\ ${ }^{2}$ Department of Chemical Engineering, Sathyabama University, Chennai, India \\ E-mail : 'renichris@yahoo.com
}

\begin{abstract}
Activated carbon is an important industrial adsorbent which finds application in pollution control, water treatment, solvent recovery and as a catalyst. The popular adsorbent is riding the coat tails of a boom spurred by tightening environmental laws. Demand is rising sharply by $7 \%$ every year, and indigenous production and characterization of activated carbon from various raw materials becomes imperative for diversified end uses. In the present work rubber wood was explored as an alternative viable source for activated carbon production. A muffle furnace was made use of and the effect of various parameters on chemical activation, steam activation and chemical activation followed by steam activation was studied. The parameters were time, reagent selection, reagent concentration and impregnation ratio. The carbon was characterized with the help of its Methylene blue number and its lodine number which gives an indication of the micro, meso and macro pore sizes. It was observed by considering only the $M$ ethylene blue number and lodine number that chemical activation followed by steam activation is better. Considering the yield it can also be concluded that activation only by the chemical method yields better results.
\end{abstract}

KEYWORDS : Activated carbon, Rubber wood, Activation, Characterization.

\section{INTRODUCTION}

Activated carbon is the key element in a number of control technologies and is an extremely effective adsorbent, because it possesses a phenomenally high surface area per unit weight ,an intricate pore structure and a primarily hydrophobic surface. Based on their applications they are classified as liquid phase carbons and vapor phase carbons. Liquid phase carbons which are used in water treatment are characterized by their macro pores. Vapor phase carbons have more micro pores and are used in the removal of gaseous pollutants and for the recovery of organic vapors from effluent gas streams [1,2].

Activation is the process by means of which greatly improved adsorptive properties are imparted to charcoal made from a variety of raw materials. An activation process is used to open up the incipient pore structure by burning away the non-graphitic carbon and it is the activation agent, the length of time over which it is used and the type of activation catalyst used ,if any, that will determine the surface area, pore size and surface chemistry that the final carbon will have.[2,3]. The raw material for charcoal manufacture can vary from coal through lignite and peat to wood, nutshells, fruit pits and still others. Recently petroleum residues have been carbonized and the resulting needle cokes activated with steam gives micro porous charcoals of very high surface area. Activation is generally a two stage process. The first stage consists of carbonization under reducing conditions below $600^{\circ} \mathrm{C}$ or simultaneous carbonization and chemical activation by impregnation with dehydrating agents such as Zinc chloride and Phosphoric acid between $400 Q C$ and $700 Q C$.[2]. Thisfirst stage may be followed by a second stage of steam activation above $850 \mathrm{Q}$ C.[1].

The prime objective of the activation process is to obtain a high grade activated carbon which has an adsorptive capacity several times as great as that of the raw material, which is mechanically strong and obtainable in good yield. The present work deals with production of activated carbon from rubber wood by chemical, steam activation ,chemical activation followed by steam activation and to study the influence of various parameters on the activated product and its characterization. Choice of the raw material is based on the easy availability and low cost. Owing to the diverse applications of the activated carbon a lot of work has been done in producing carbons for specific industrial applications. They are termed as tailor made carbons. The objective of the present work is to make such a tailor made carbon from rubber wood.

\section{MANUFACTURING PROCESS}

Activation is affected on any carbonaceous material with the help of either one or more of the following steps and the present work is based on all the three.
A. Steam activation
B. Chemical activation
C. Chemical activation followed by steam activation.

\section{A. Chemical Activation}

This is achieved by impregnating the raw materials with dehydrating salts zinc chloride or acids like 
phosphoric acid and carbonizing them at high temperatures. In this process, zinc chloride and phosphoric acid of various concentrations are mixed with a known weight of rubberwood. The mixture is then dried at $120^{\circ} \mathrm{C}$ for one hour, and then activated at $400^{\circ} \mathrm{C}, 500^{\circ} \mathrm{C}, 600^{\circ} \mathrm{C}$ for 15,30 and $60 \mathrm{~min}$. Then the product is washed with acid and water in case of zinc chloride and water in case of phosphoric acid and then it is dried and ground.

\section{B.Steam Activation}

In steam activation, the carbonaceous material is heated at very high temperature $\left(700-900^{\circ} \mathrm{C}\right)$ with suitable gases. The most commonly used being steam, $\mathrm{CO}_{2}$ and a mixture of these two. Experimental data indicate that steam is eight times as reactive as $\mathrm{CO}_{2}$.Activation of carbons with steam improves the desirable properties like pore volume and surface area and hence improves the retentivity of organic vapors on carbon.

\section{C.Chemical Activation followed by Steam Activation}

It is a combination of both chemical activation and steam activation. The raw material is impregnated with the dehydrating reagent. Then it is heated to $120^{\circ} \mathrm{C}$ followed by steam and then it is washed to recover the solvent.

\section{EXPERIMENTAL PROCEDURE}

\section{A.Raw Material}

The carbonaceous source made use of for the present experimental study is rubber wood. The choice of the raw material was made based on its ease of availability and currently having no valuable end use. Rubber wood was processed from Kerala where it is periodically cultivated. The wood is used for the study after the removal of latex. The wood was usually used for making crates and for firewood. So it was decided to make use of it for a better purpose.

\section{B.Static Bed Reactor}

The static bed consists of a muffle furnace which can be operated over a wide temperature range(30$1000^{\circ}$ ). The reactor vessels are two silica crucibles with a volume of $50 \mathrm{ml}$ each. The temperature is controlled with an accuracy of $\pm 2 \mathrm{C}$ by means of a temperature controller. A thermocouple measures the bed temperature. Provision is made for maintaining the required gas atmosphere.

\section{C.Process Description}

The experimental work is based on chemical activation ,steam activation and chemical activation followed by steam activation. The stages involved in chemical activation and steam/chemical activation are
1. Pre carbonization

2. Carbonisation

3. Post carbonization

\section{Pre Carbonization}

Rubber wood chips are collected, ground and sieved to get the required size fraction. A amount of the raw material is soaked in solutions of different weight percentage of either zinc chloride or phosphoric acid. The mixture was allowed to soak for $24 \mathrm{hrs}$. The solution was then decanted. The mixture was then dried at $120^{\circ} \mathrm{C}$ for one hour. The sample is now impregnated and ready for activation.

\section{Carbonization orActivation}

Nitrogen from the gas cylinder is fed to the muffle furnace in order to maintain an inert medium .The impregnated sample is placed in this the muffle furnace. With the help of the temperature controller the temperature within the furnace is maintained at different temperatures. The activation is carried for a known period of time. The heating is cut off and it is allowed to cool to the ambient temperature. The activated carbon is removed.

\section{Post Carbonization}

The activated carbon obtained after each experiment was washed with $0.1 \mathrm{~N} \mathrm{HCl}$ to recover the impregnated reagent zinc chloride. It was then washed repeatedly with distilled water to remove chloride ions. When the impregnated reagent is $\mathrm{H}_{3} \mathrm{PO}_{4}$, the recovery is done with repeated washing with distilled water. The washed sample was dried in an air oven for $24 \mathrm{hrs}$ and stored for analysis.

All the above steps were followed for chemical activation and chemical followed by steam activation while the activation step alone is followed for steam activation.

\section{CLASSIFICATION}

Based on their applications, they are classified as Liquid phase carbons and Vapor phase carbons.

Liquid phase carbons are used for the removal of impurities from liquids. Vapor phase carbons are used for the removal of gaseous/pollutants and condensate vapors from gas pollutant gas streams. The difference between the two carbons types are based on pore diameter. Pores greater than $50 \mathrm{~nm}$ are classified as a nana pores, those between $2-50 \mathrm{~nm}$ as micropores. It was found that vapor phase carbons have micropores and liquid phase carbons having more of micro and macro pores .Consequently, particular attention is paid to this during manufacture. It depends on the type of raw material used and the method of activation. 


\section{EVALUATION}

\section{A.Methylene Blue Number}

About $0.1 \mathrm{~g}$ of material is weighed accurately and transferred to a $50 \mathrm{ml}$ glass stoppered flask. $10 \mathrm{ml}$ of methylene blue solution is added from a burette and the flask is well shaken for 5 minutes. After the first $10 \mathrm{ml}$ is decolorized, methylene blue solution is continually added till the blue color does not disappear after 5 minutes. Decolorizing power of carbon is expressed in terms of milligrams of methylene blue adsorbed by one $\mathrm{gm}$ of activated carbon..

\section{B.lodine number}

lodine number is defined as the milligrams of iodine adsorbed by one gm of activated carbon. About $0.5 \mathrm{~g}$ of activated carbon is accurately weighed into a clean and dry conical flask. To this $50 \mathrm{ml}$ of iodine solution is added. The conical flask is kept in a shaker fro 45 minutes. The carbon is then filtered and the filter paper is washed thoroughly before estimating the unadsorbed iodine iodimetrically by titrating it against standard thiosulphate solution using starch as an indicator.

\section{C.Yield}

Yield obtained is a measure of the process efficiency and is important in plant economics. This is the weight percent of activated carbon obtained after washing and drying in a single operation.

\section{RESULTS AND DISCUSSION}

The main aim of this present study is to determine the extent of activation of rubber wood as to yield activated carbon that would have commercial value. In the present study it was intended to determine the best method of activation to yield the desired product. The results are given under three titles based on the method of activation.

\section{A. ChemicalActivation}

It was observed that as the reagent concentration is increased there is an increase in the impregnation ratio. With an increase in reagent concentration there is a marked increase in the Methylene blue number. lodine number does not increase appreciably with increase in reagent concentration. Yield increases with increase in reagent concentration. As temperature is increased in the case of phosphoric acid Methylene blue number increases but it decreases with zinc chloride. It was observed that zinc chloride yields carbons with much higher iodine numbers than that produced using phosphoric acid as the chemical reagent. For chemical activation alone the best products pertaining to Methylene blue number that means that liquid phase application oriented is obtained at carbonization temperature of $600^{\circ} \mathrm{C}$ when the chemical reagent is phosphoric acid of $75 \%$ concentration and carbonization time of $30 \mathrm{~min}$. However, if the product required are vapour phase carbons, zinc chloride has to be the reagent with $75 \%$ concentration, $400^{\circ} \mathrm{C}$ carbonization temperature and $60 \mathrm{~min}$.

\section{B. SteamActivation}

When the method of activation is purely by steam activation it can be concluded that carbons with higher Methylene Blue Number namely liquid phase carbons can be obtained by operating the system at $900^{\circ} \mathrm{C}$ and for carbonization time of $10 \mathrm{~min}$. However it should be noted that this has the minimum yield of approximately $12 \%$. Hence the alternative choice would be to use steam activation at $700^{\circ} \mathrm{C}$ for $5 \mathrm{~min}$ where a yield of $18 \%$ could be obtained. For vapor phase carbons identified by iodine number at $900^{\circ} \mathrm{C}$ carbonization temperature with $5 \mathrm{~min}$. time yields the highest lodine number. However the yields are poor approximately $14 \%$. The yield at $700^{\circ} \mathrm{C}$ and $10 \mathrm{~min}$ is relatively higher about $24.5 \%$. However the carbon produced has relatively much lower values of lodine No. 920.Depending on the end use a judicial choice of the operating conditions can be made.

\section{Chemical Activation followed by Steam Activation.}

When the method of activation is chemical followed by steam it can be observed that liquid phase carbons of qualities much better than the other two methods are obtained when the reagent is zinc chloride of $75 \%$ concentration with operating conditions of $900^{\circ} \mathrm{Cand} 10$ min. However, the yields are as low as $8 \%$. Considering the yield the choice of phosphoric acid at $700^{\circ} \mathrm{C}$ and of $75 \%$ concentration with carbonization time of $10 \mathrm{~min}$ yields carbons of Methylene Blue No. approximately 110 but with very large yields as high as $60 \%$.lodine No. are again the highest 1375 when the reagent is zinc chloride of concentration of $75 \%$ operating at $900^{\circ} \mathrm{C}$ and for $10 \mathrm{~min}$. The yields are low. Since the differences between lodine numbers obtained by zinc chloride and phosphoric acid are very large an alternative choice cannot be easily proposed.

\section{CONCLUSION}

From the present work it can be concluded that rubber wood yields activated carbon that can be used commercially. Of the three methods of activation it can be observed that chemical activation followed by steam activation yields better activated carbon than when the method of activation is only chemical or only steam activation. Better activated carbon means carbons having both Methylene blue number and lodine number than the other methods. Hence it can be concluded that since the 
yields are also to be considered along with the quality of carbon produced chemical activation followed by steam activation using zinc chloride would not be the choice. It is found that only chemical activation yields reasonably good results i.e. using phosphoric acid mehtylene blue values of 130 at operating temperature of $600^{\circ} \mathrm{C}$ and time of 30 mins. and yields are as high as $86 \%$.If the vapor phase carbons are required the choice of the reagent has to be zinc chloride of $75 \%$ concentration at operating temperature of $400^{\circ} \mathrm{C}$ for 60 min since the lodine number obtained was 1100 . The yields were as high as $70 \%$.

\section{REFERENCES}

[1] C.L.Mantell .." Carbon and graphite Handbook," Interscience publishers, 1968.

[2] J.W.Hassler,.,. " Activated carbon," Chemical Pub. Company Inc. , 1977.

[3] Ullmann's Encyclopedia of Industrial Chemistry, VCH Publishers,vol.A5,1986.

[4] R.V.Carubba ,.J.E. Urbanic,.N.J.Wagner, and R.H.Zanitsch, "Perspectives of cativated carbonpast Present and future,"AIChE, Sym. Ser.,vol 80 ,pp.76-83, 1980.

[5] T.J.Seaburn and A.J.Engel," Sorption of sulphur dioxide by suspension of activated carbon in water,"AIChE Sym. Ser.,vol.69,pp.71-75,1973.

[6] Dietz Victor ," Bibliography of solid adsorbents", National Bureau of Standards,vol.1,1944.

[7] M.Smisek and S.Cerny," Activated Carbon," American Elsevier, 1970.

[8] S.Mukerjee and S.Bhattacharya ," Effect of chemical treatment on the properties of activated charcoal," J.Am. Chem.Soc.,vol.71,pp.373377,1951.

[9] H.Tengten," New applications for carbonaceous adsorbents," Carbon,vol.15,pp.273,1977.
[10] S.Banerjee,S.Majumdar,S.Dutta," Activated carbon from coconut shells, Ind.Chem. Engg.,vol.13,pp.637, 1974.

[11] O.Olaofe and H.Bosch," The production and characterization of activated carbon from tropic carbonaceous materials," Chem.Age of India,vol.31, pp.238-242,1980.

[12] ....MortleyWA.Mellows and S.Thomas,"Activated carbon from materials of varying morphologhical structure, "Thermochemica Acta,vol.129,pp.173186, 1988.

[13] John Kirubakaran,C.Krishnaiah and S.K.Seshadri, "Experimental study of the production of actiavetd carbon form coconut shells in a fluidized bed reactor," Ind.Eng.Chem.,vol.30,pp.2411-2416,1991.

[14] A.Bosch and M.Lewin," The influence of fine structure on the pyrolysis of cellulose-1vacuum pyrolysis,J.Poly. Sci.,vol.11,pp.3071-3093,1993.

[15] A.V.Natu," Pilot plant studies using granular activated carbon,Chem Ind. Digest,pp.7679,1998 .

[16] Hsisheng Teng and Hung-Chi Lin,"Activated carbon production form low ash sub-bituminous coal with carbon dioxide activation," AIChE,PP.1170-1176,1998.

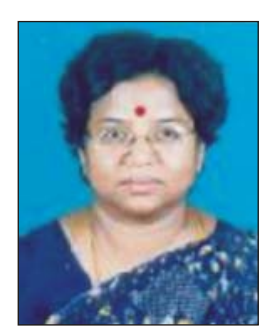

Dr.Lima Rose Miranda, is an Assistant Professor in the Department of Chemical Engineering, AC Tech, Anna University and has twenty years of teaching and research experience . Her area of research is Chemical Kinetics, Activated Carbon and Water treatment. She has several National and International Papers to her credit 